\title{
Metas do Conselho Nacional de Justiça 2012/2013: uma análise dos contornos gerenciais assumidos pela reforma do Poder Judiciário no Brasil
}

Gabriel Astoni Sena

Tribunal Regional Eleitoral de Minas Gerais (TRE-MG)

Metas do Conselho Nacional de Justiça 2012/2013: uma análise dos contornos gerenciais assumidos pela reforma do Poder Judiciário no Brasil

Este artigo tem como objetivo avançar no estudo do processo de reforma do Poder Judiciário brasileiro, o qual se insere no processo de reforma do Estado pátrio. A partir das contribuições de Osborne e Gaebler (1992) e Abrucio (2006), buscou-se traçar um paralelo entre as lógicas gerencial e fiscal e esclarecer como as mesmas refletiram nos indicadores de eficácia, eficiência e efetividade do Poder Judiciário no Brasil. Para atingir o objetivo proposto, optou-se por utilizar como método a análise de conteúdo de Bardin (2002), pela regra de enumeração do tipo frequência, buscando, com isso, observar o papel que o Conselho Nacional de Justiça exerceu nesse processo e a lógica do plano de metas estabelecido pela instituição para os anos de 2012 e 2013. Como resultado, observou-se que as metas estabelecidas para o biênio buscaram implantar uma gestão mais eficaz nesse núcleo estratégico do Estado, com ênfase na celeridade processual, gestão administrativa e informatização dos procedimentos. Percebeu-se que a lógica gerencial continua exercendo grande influência no modelo de gestão adotado. Como novidade, verificou-se a inserção de indicadores de efetividade, os quais podem permitir aproximar os objetivos dessa esfera de poder com os da sociedade brasileira, repercutindo na elaboração de metas futuras.

Palavras-chave: poder judiciário, reforma judiciária, administração pública, eficiência, eficácia

Artigo recebido em abril de 2013. Versão final em abril de 2014. 


\section{Objetivos del Consejo Nacional de Justicia 2012/2013: un análisis de los contornos de gestión asumidos por la reforma Judicial en Brasil}

En este artículo se pretende avanzar en el estudio de la reforma del Poder Judicial brasileño, que forma parte de la reforma del proceso de Estado patrio. A partir de los aportes de Osborne y Gaebler (1992) y Abrucio (2006), hemos tratado de establecer un paralelismo entre las lógicas fiscales y de gestión y cómo se reflejan los indicadores de eficacia, eficiencia y eficacia del sistema judicial en Brasil. Para lograr el objetivo propuesto, se optó por utilizar como método el análisis de contenido de Bardin (2002), a través de la regla de enumeración del tipo frecuencia, buscando con ello observar el papel que el Consejo Nacional de Justicia (CNJ) ejerce en este proceso y la lógica del plan de metas establecido por la institución para los años 2012 y 2013. Como resultado, se observó que los objetivos establecidos para el bienio intentaron desplegar una gestión más eficaz en este núcleo estratégico del Estado, con énfasis en la puntualidad, la gestión administrativa y la informatización de los procedimientos. Se observó que la lógica empresarial sigue ejerciendo gran influencia en el modelo de gestión adoptado. Como novedad, se produjo la inclusión de indicadores de efectividad, lo que puede permitir aproximar los objetivos de esta esfera de poder con la sociedad brasileña, lo que refleja la elaboración de metas futuras.

Palabras-clave: poder judicial, reforma judicial, administración pública, eficiencia, eficacia

\section{Goals of the National Council of Justice/Brazil 2012/2013: an analysis of the Judicial reform in Brazil}

This article aims to advance the study of the reform of the Brazilian Judiciary branch, which is part of the country's state reform process. From the contributions of Osborne and Gaebler (1992) and Abrucio (2006), we sought to draw a parallel between the fiscal and managerial logics and how they were reflected in the indicators of efficacy, efficiency and effectiveness of the Brazilian Judiciary branch. We used the content analysis method of Bardin (2002) by enumeration of frequency rule type, seeking thereby to observe the role that the National Council of Justice exercised in this process and the logic goals of the plan established by it for the years 2012 and 2013. As a result, we observed that the goals set for the biennium sought to deploy a more effective management in this strategic core of the state, with an emphasis on promptness, administrative management and computerization of procedures. We also noticed that the managerial logic continues to exert great influence on the management model adopted. As a novelty, there was the inclusion of indicators of effectiveness, which may allow the goals of the Judiciary branch to be more close to those of the Brazilian society, having an impact on the elaboration of future goals.

Keywords: judiciary branch, judiciary reform, public administration, efficiency, efficacy 


\section{Introdução}

A reforma do Poder Judiciário no Brasil passou a ser tratada como uma questão de Estado. Abandonou-se o discurso e foi iniciado um ousado processo de modernização desse núcleo estratégico do Estado, o qual tem como marco inicial a publicação da Emenda Constitucional n 4, de 2004.

A morosidade, ineficiência e falta de transparência, características marcantes do Judiciário brasileiro, resultaram de um longo período de inércia administrativa, em que as reformas que acompanharam a gestão pública no Brasil e no mundo foram colocadas em segundo plano nessa esfera de poder (PInHeIRo, 2003; Renault, 2005).

Renault (2005) afirma que, de todas as instituições do Estado, o Poder Judiciário foi a que menos se modernizou, seja por falta de recursos ou por falta de compreensão do papel fundamental que exerce em favor da cidadania.

Esse cenário começou a ser alterado com a criação do Conselho Nacional de Justiça (CNJ), órgão inserido na estrutura do Poder Judiciário, o qual recebeu da Constituição Federal as atribuições de fiscalizar e controlar as atividades administrativas dos órgãos judiciais no País.

A resistência natural ao novo também foi percebida com a criação do órgão, o qual ficou responsável por iniciar o processo de reforma no Judiciário brasileiro. Machiavelli (2006, p.26) alertou que "aquele que a introduz terá por inimigos todos os que da velha ordem extraíam privilégios e por tímidos defensores todos os que das vantagens da nova ordem poderiam usufruir". A própria Associação dos Magistrados do Brasil (AMB) impetrou uma ação direta de inconstitucionalidade no Supremo Tribunal Federal (ADI 3367/2004) questionando o nascimento do CNJ, sob o argumento de que a criação de um órgão de cúpula, formado por representantes de outros poderes, ofenderia os princípios da separação e independência dos poderes, além de atentar contra o pacto federativo.

As tentativas de deslegitimar esse novo e inovador órgão foram infrutíferas. Após nove anos de sua criação, o CNJ começa a apresentar os primeiros resultados de seu ousado plano de metas, o qual inclui medidas que visam dar maior eficácia à prestação jurisdicional, traduzida na efetivação do princípio da razoável duração dos processos, além de metas que privilegiam uma gestão mais eficiente, oferecendo um serviço público menos oneroso para a sociedade brasileira.

Além das citadas metas, há também importantes medidas que visam dar transparência à atividade jurisdicional, preparar magistrados e servidores para a gestão administrativa dos tribunais, além de informatizar os serviços judiciais. Esse conjunto de estratégias tem por finalidade implantar uma cultura de planejamento e gestão nesse poder. Além disso, os resultados do plano de metas 
servirão como importante instrumento para que os gestores do Poder Judiciário elaborem políticas de gestão estratégica e avaliem as demandas dos órgãos jurisdicionais, criando subsídios para a criação de cargos e ações voltadas para melhorar a estrutura física dos tribunais.

Nesse contexto, a finalidade do presente estudo é verificar como o panorama da reforma do Estado afetou o Judiciário brasileiro, buscando responder à seguinte questão: qual a lógica da reforma do Poder Judiciário no Brasil, tendo como foco as metas estabelecidas para os anos de 2012 e 2013 ?

O texto procura analisar aspectos referentes à reforma do Estado no Brasil e como a mesma atingiu o Poder Judiciário pátrio. Por meio de conceitos ligados à administração pública gerencial, será traçado um panorama do perfil da reforma do Poder Judiciário brasileiro, verificando como as variáveis da eficiência, eficácia e efetividade influenciaram na elaboração das metas traçadas pelo CNJ. Como opção metodológica, optou-se por realizar uma análise de conteúdo, utilizandose a regra de enumeração do tipo frequencial (BARDIN, 2002).

O presente estudo revela-se importante tendo em vista que a reforma do Poder Judiciário passou a ser tratada como uma questão de Estado (PINHEIRO, 2003; RenAULt, 2005) e os resultados apresentados pelo CNJ carecem de uma análise mais profunda, conforme demonstrado por Sena, Silva e Luquini (2012).

O presente artigo foi elaborado em cinco seções, além desta introdução. $\mathrm{Na}$ seção seguinte, serão feitas considerações sobre a reforma do Estado no Brasil, abordando a lógica fiscal e gerencial, e os indicadores de eficiência, eficácia e efetividade. Já na seção "A reforma do Judiciário", o tema em tela será a reforma no âmbito do Poder Judiciário brasileiro e a atuação do CNJ. A penúltima parte concentrar-se-á no estudo da metodologia empregada, com a inserção das metas estabelecidas pelo órgão para o biênio 2012/2013. Por fim, será feita a análise dos dados e a última seção será dedicada às considerações finais e à agenda de pesquisa.

\section{Considerações sobre a reforma do Estado no Brasil}

Com o incremento das atribuições governamentais e o crescimento das demandas sociais, o modelo burocrático, que funcionava a contento no Estado liberal, mostrou-se ineficiente.

Dessa forma, o citado modelo começou a passar por um processo de substituição, o qual foi acelerado, a partir da década de 1970, com o agravamento da crise fiscal, que obrigou as nações a repensarem o modelo burocrático de 
administração pública até então predominante, como medida urgente e necessária para reduzir o custo do Estado e tornar os serviços públicos mais eficientes.

Nesse contexto, surgiu o modelo de administração gerencial, o qual possui raízes nas reformas ocorridas na Grã-Bretanha (1979), EUA (1980) e Nova Zelândia (1984), pregando a ruptura com o modelo burocrático, defendendo uma redução drástica dos custos do setor público com a finalidade de aumentar a sua produtividade.

Como todo processo de mudança, a reforma do Estado carece de um forte apoio político e social, sob pena de sofrer um processo de crise. Abrúcio (2006) salienta que o caráter político desse processo muitas vezes é submerso pelo linguajar técnico que esconde o seu potencial conflitivo.

No Brasil, um novo modelo de administração pública começou a ser implantado em 1995, com a criação do Plano Diretor da Reforma do Aparelho do Estado (PDRAE), cuja proposta básica era transformar a administração pública brasileira de burocrática para gerencial.

Enquanto a administração pública burocrática concentra-se no processo, definindo os procedimentos para contratação de pessoas, compra de bens e serviços com a finalidade de satisfazer as demandas dos cidadãos; a administração pública gerencial tem como objetivo final os resultados (PAULA, 2005; BRESSER-PEREIRA, 2006; Keinert, 2006; Matias-Pereira, 2009; Secchi, 2009).

O PDRAE definiu, expressamente, o significado da reforma do Estado:

Reformar o Estado significa melhorar não apenas a organização e o pessoal do Estado, mas também suas finanças e todo o seu sistema institucionallegal, de forma a permitir que o mesmo tenha uma relação harmoniosa e positiva com a sociedade civil. A reforma do Estado permitirá que seu núcleo estratégico tome decisões mais corretas e efetivas, e que seus serviços tantos os exclusivos, quanto os competitivos, que estarão apenas indiretamente subordinados na medida que se transformem em organizações públicas não estatais - operem muito eficientemente (DI PIETRO, 2002, p. 84).

A proposta de reforma da máquina pública brasileira partiu da existência de quatro setores básicos, integrantes da estrutura estatal: a) o núcleo estratégico do Estado; b) as atividades exclusivas de Estado; c) os serviços não exclusivos ou competitivos; e d) a produção de bens e serviços para o mercado (BRESSER-PEREIRA, 2006).

Dentro dessa classificação, o núcleo estratégico seria composto pelos órgãos públicos nos quais são definidas as leis, as políticas públicas de interesse do País e as decisões dos órgãos julgadores. Em nível federal, o núcleo é formado pelo 
Presidente da República, pelos ministros de Estado e cúpula dos ministérios, pelo Legislativo (Câmara e Senado), pelos tribunais da União e pelo Ministério Público da União.

Já as atividades exclusivas de Estado seriam aquelas em que os poderes exclusivos do Estado, tais como o de tributar, de defesa e de polícia, se fizerem presentes. Dessa forma, teríamos como exemplos as polícias, forças armadas e órgãos de fiscalização e regulamentação.

A terceira categoria apresentada, os serviços não exclusivos ou competitivos do Estado, engloba aqueles que, embora não envolvam o poder de Estado, são realizados ou subsidiados por ele, tendo em vista a relevância que representam para os direitos da pessoa humana, ou por envolverem economias externas. Portanto, tendo em vista que tais serviços não podem ser adequadamente recompensados pelo mercado, o Estado assumiria a sua execução.

Por fim, há a produção de bens e serviços para o mercado, a qual é realizada pelo Estado por meio das suas empresas públicas e sociedades de economia mista, as quais atuam prestando serviços públicos para a sociedade ou em setores considerados estratégicos, tal como o do petróleo.

Tendo em vista que o objetivo geral da reforma administrativa é transitar de uma administração pública burocrática para a gerencial, é necessário que haja a combinação de princípios presentes nesses dois modelos. A segurança e a efetividade, qualidades presentes no modelo burocrático, devem ser preservadas no núcleo estratégico; porém, devem-se agregar os conceitos da administração pública gerencial. Já nos demais setores, tendo em vista a relevância do requisito eficiência, em virtude da existência de grande número de servidores, cidadãosclientes e usuários envolvidos, o peso da administração burocrática deve ir diminuindo, até praticamente desaparecer, como no caso das empresas estatais (Bresser-Pereira, 2006).

Portanto, o Poder Judiciário, segundo a classificação da reforma da administração pública proposta por Bresser-Pereira (2006), é definido como integrante do núcleo estratégico do Estado, devendo o modelo gerencial ser construído aproveitando as qualidades do modelo burocrático, como forma de preservar suas conquistas. Com isso, será possível oferecer à sociedade brasileira um serviço público com elevado grau de eficiência e eficácia.

É importante consignar, também, que a reforma da administração pública deve ser executada em três dimensões, a saber: a) institucional-legal; b) cultural; e c) cogestão (BREsSER-Pereira, 2006). 
Através da dimensão institucional-legal, a Constituição e a legislação pertinente à administração pública devem ser alteradas. No Brasil, a reforma do Estado foi efetivada com a publicação da Emenda Constitucional no 19, de 1998, a qual modificou o regime vigente, incluindo princípios e normas ligados à administração pública gerencial, gerando reflexos nas políticas ligadas aos servidores públicos e agentes políticos, controle de despesas e finanças públicas, buscando efetivar as diretrizes propostas no PDRAE.

No tocante à reforma do Judiciário, a dimensão institucional-legal foi efetivada com a publicação da Emenda Constitucional no 45, de 2004. Essa alteração constitucional incluiu diversos pontos, desde a organização estrutural do Poder Judiciário, até questões ligadas à competência dos órgãos jurisdicionais, visando, com isso, oferecer à sociedade brasileira uma justiça mais célere e transparente.

Já a dimensão cultural buscou sepultar os resquícios patrimonialistas que insistiam em permanecer na gestão pública brasileira e fazer a transição do modelo burocrático para o gerencial, a qual exige uma mudança de atitude, tanto da sociedade quanto dos servidores públicos (TORRES, 2004; LuSTOSA DA COSTA, 2010). Abrucio (2006) afirma que a estratégia de implementação da reforma deve levar em conta o convencimento de dois setores importantíssimos, muitas vezes negligenciados por propostas essencialmente tecnocratas: os funcionários públicos e a população.

Essa necessidade de mudança cultural, e consequente resistência por parte dos interessados, foi fortemente percebida durante o processo de reforma do Poder Judiciário, que, apesar de ser extensamente debatido e considerado estratégico para o Estado brasileiro, quando de sua implantação, sofreu resistência da $A M B$, com a citada ADI 3367, a qual tentou impedir as mudanças necessárias.

Por fim, a dimensão da cogestão está atrelada à ideia de criação das agências autônomas, no nível das atividades exclusivas de Estado, e das organizações sociais, no setor público não estatal, ou seja, nas organizações privadas que atuam em atividades públicas. Bresser-Pereira (2006) considera essas duas tarefas estratégicas, como forma de pôr em prática novas ideias gerenciais e oferecer à sociedade um serviço público de fato mais barato, mais bem controlado e de melhor qualidade.

\section{Lógica fiscal versus lógica gerencial}

Abrucio (2006), ao descrever o processo de reforma da administração pública, trabalha com duas lógicas antagônicas, as quais aparecem como alternativas 
para a escassez de recursos vivida pelos Estados contemporâneos: a fiscal e a gerencial.

A lógica fiscal tem como finalidade controlar os inputs do sistema como mecanismo de contenção dos custos. Já a gerencial, busca aumentar a eficiência e a efetividade, de tal forma que sua lógica se concentra no alcance de seus objetivos, ou seja, obter melhores outputs. Nesse diapasão, enquanto a lógica fiscal voltase para o custo do serviço público, atuando no curto prazo, a lógica gerencial almeja tornar a ação estatal mais produtiva. Para isso, é necessário um amplo processo de profissionalização dos funcionários públicos e de modernização da máquina administrativa, medidas que somente dão resultados a médio e longo prazos.

É importante ressaltar que os mecanismos contratuais, pilares da administração gerencial, perdem sua efetividade quando a lógica fiscal se sobrepõe à lógica gerencial, tornando-se dominante. Abrucio (2006) alerta que, quando esse dilema não é resolvido, a implementação integral da lógica gerencial no serviço público é inviabilizada.

As organizações públicas transformam os recursos do Estado em serviços públicos, com o objetivo de satisfazer as demandas da sociedade. O desempenho dessas organizações é indicado por meio de dois conceitos largamente utilizados na esfera privada: eficiência e eficácia. Soma-se a eles o critério da efetividade, o qual busca responder às demandas da sociedade, combinando índices de eficiência com eficácia.

O conceito de eficácia não está diretamente ligado aos meios ou à forma, mas sim ao cumprimento dos resultados pelas organizações. Dessa forma, a organização será mais eficaz na medida em que o índice de realização de seus objetivos for mais elevado, ou seja, quando seus sistemas realizarem seus fins (OSBORNE; GAEBLER, 1992; Lacombe; Heilborn, 2003; Maximiniano, 2006).

Já eficiência é o termo empregado quando a organização utiliza economicamente seus recursos. É a relação entre os insumos aplicados e os resultados produzidos. Quanto mais alto o grau de produtividade ou economia na utilização dos recursos, maior é o índice de eficiência da organização.

Moraes (2001), ao abordar o conceito de eficiência, afirma que o mesmo transformou-se num princípio constitucional, com a publicação da Emenda Constitucional $n^{\circ} 19$.

Di Pietro (2002, p.83) explica que o citado princípio possui dois aspectos centrais:

O princípio da eficiência na Administração Pública apresenta dois aspectos centrais: pode ser considerado em relação ao modo de atuação do agente público, do qual se espera o melhor desempenho possível de suas 
atribuições, para lograr os melhores resultados; e em relação ao modo de organizar, estruturar, disciplinar a Administração Pública, também com o mesmo objetivo de alcançar os melhores resultados na prestação do serviço público.

No tocante às organizações públicas, o grande dilema da reforma gerencial é adequar o binômio eficácia-eficiência, de forma a oferecer um serviço público de qualidade para a sociedade, mas, ao mesmo tempo, economicamente viável para o Estado.

Abordando o modelo gerencialista puro, Abrucio (2006) afirma que os critérios de medição da eficiência podem tornar-se tão rígidos quanto as regras e os procedimentos do modelo burocrático weberiano, levando à ineficácia e à falta de capacidade adaptativa (ABrucıo, 2006).

Enfocar apenas a eficiência governamental acarreta outro problema: não se atribui à avaliação da efetividade dos serviços públicos a devida importância. Efetividade é entendida aqui como o grau em que se atingiram os resultados esperados (Osborne; Gaebler, 1992). Portanto, o conceito de efetividade, ao contrário de eficiência pura, não é econômico, e sim de avaliação qualitativa dos serviços públicos (Aвrucıo, 2006).

Portanto, o conceito de efetividade deve ser entendido como aquele que combina os objetivos da organização com o atendimento das necessidades sociais, pressupondo certo grau de eficiência e eficácia.

Neste trabalho, o termo efetividade não será utilizado como sinônimo de eficácia, o qual resulta da tradução inglesa do termo effectiveness, mas, sim, como o significado das necessidades de produtos e serviços das organizações e do Estado por parte dos clientes e da sociedade.

Abrucio (2006, p. 184) esclarece que:

Com o conceito de efetividade, recupera-se a noção de que o governo deve, acima de tudo, prestar bons serviços. É a ótica da qualidade que começa a ser incorporada pelo modelo gerencial. Porém, a valorização do conceito de efetividade também traz de novo à tona o caráter político da prestação de serviços públicos, uma vez que são os usuários dos equipamentos sociais que de fato podem avaliar a qualidade dos programas governamentais. $\mathrm{E}$ aqui está um dos calcanhares-de-aquiles do modelo gerencial puro: a subestimação do conteúdo político da administração pública.

Em suma, ao optar por uma determinada vertente reformista, o gestor público deve saber ponderar os índices de eficiência e eficácia, para tentar oferecer à 
sociedade um serviço público de qualidade, sem descuidar do caráter econômico do mesmo. Além disso, a efetividade, a qual resulta na atribuição de valor social ao serviço público ofertado pelo Estado, também deve ser inserida nesse contexto de reforma, sob pena de termos uma gestão eficiente e eficaz, mas não efetiva.

No âmbito do Poder Judiciário, a lógica gerencial se relaciona com as mudanças estruturais que visam entregar à sociedade o produto desse núcleo estratégico: a Justiça. Essas mudanças vão desde alterações na legislação processual, que visam reduzir a morosidade na tramitação dos processos, até a modernização do aparelho judicial, o qual é excessivamente fragmentado, não havendo troca de experiências entre os tribunais.

Na seara legislativa, a criação da súmula vinculante, que aumenta a previsibilidade da Justiça e acelera os processos, e do instituto da repercussão geral, que permite ao STF analisar apenas as causas em que há interesse da sociedade como um todo, poderá reduzir de forma significativa o tempo médio dos processos e eliminar cerca de $50 \%$ das ações em curso no País (PINHeIro, 2003).

Já a lógica fiscal se utiliza de instrumentos de cunho econômico que buscam reduzir o custo da prestação jurisdicional. Ações voltadas para a redução da máquina administrativa e controle de gastos com vencimentos e subsídios de servidores e magistrados são exemplos de ações voltadas para o Poder Judiciário que se amoldam à lógica fiscal.

A compreensão desses conceitos é de fundamental importância para o presente estudo, tendo em vista que o seu objetivo é compreender qual é a corrente teórica, a lógica administrativa adotada como norteadora da reforma do Poder Judiciário para os anos de 2012 e 2013.

\section{A reforma do Judiciário}

A onda reformista experimentada pelo Estado brasileiro não se limitou ao Poder Executivo. O Poder Judiciário também foi alvo de uma extensa reforma, a qual alterou, não apenas alguns procedimentos judiciais, mas também a própria estrutura desse poder. O marco dessa reforma foi a criação do Conselho Nacional de Justiça (CNJ), órgão que passou a ser o responsável pela fiscalização financeira e administrativa do Poder Judiciário.

As medidas adotadas compreenderam, basicamente, o desenvolvimento de três conjuntos de ações coordenadas: diagnóstico, alteração legislativa e modernização.

Na ocasião das reformas, o Poder Judiciário enfrentava uma crise de credibilidade, a qual foi resultado de décadas de uma gestão ineficiente, lentidão 
na prestação jurisdicional, resultando num serviço público caro, pouco democrático e desprovido de transparência (PInheIRo, 2003; Renault, 2005).

Entre os problemas apontados por Renault (2005) estão: a) lentidão na tramitação dos processos judiciais; b) obsolescência administrativa; c) dificuldade de acesso; d) complexidade estrutural; e) concentração de litigiosidade; e f) desarticulação institucional.

Em linhas gerais, sem pretender aprofundar a discussão acerca dos problemas enfrentados pelo Poder Judiciário brasileiro, a lentidão na tramitação dos processos judiciais decorre da existência no País de um complexo sistema jurídicolegal, que prioriza os procedimentos em detrimento da satisfação da pretensão judicial. Com isso, os processos se arrastam por anos e os operadores do direito abusam de mecanismos protelatórios, os quais, muitas vezes, corroem todas as expectativas dos demandantes, gerando um alto custo social e financeiro.

Por sua vez, a obsolescência administrativa decorre da dificuldade histórica desse órgão em se modernizar, implantar novas tecnologias, visando oferecer um serviço público de qualidade para a população.

Já a dificuldade de acesso decorre do próprio custo desse serviço, o qual não leva em consideração as peculiaridades regionais, inviabilizando o acesso da população mais carente à justiça no País. Além disso, por mais que existam muitos tribunais e juízos de primeira instância, os mesmos se concentram em cidades de médio e grande porte, existindo centenas de cidades no País sem qualquer estrutura judicial, nem mesmo itinerante.

Outro problema apontado é a complexidade estrutural, que é fruto da própria Constituição Federal, a qual abraçou a evolução das instituições ao longo dos anos, buscando atender a diversos interesses classistas (PInHeIRo, 2003; Renault, 2005). Dessa forma, o Brasil apresenta 91 tribunais com grande nível de autonomia administrativa e pouca interligação entre eles, fato que gera confusão para a sociedade, e conflitos de competência para os operadores do direito, contribuindo para a lentidão processual.

A concentração de litigiosidade é mais um problema apontado e decorre da excessiva concentração de processos que respondem a interesse das grandes corporações empresariais e financeiras, da União, Estados e Municípios, congestionando grande parte dos tribunais do País.

Por fim, a desarticulação institucional é mais um problema verificado na estrutura do Poder Judiciário brasileiro e decorre da ausência de envolvimento dos agentes públicos no trato das questões relativas ao sistema judicial. Renault (2005) afirma que os problemas do Judiciário sempre foram tratados pelos magistrados e pelas associações de classe como questões interna corporis. 
Os fatos apontados revelam a extensão e a amplitude dos problemas existentes nessa esfera de poder. Esse panorama retrata um longo processo de isolamento experimentado pelo Poder Judiciário no decorrer dos anos, o qual foi agravado pela falta de articulação institucional na busca por solução dos problemas.

Com as inovações trazidas pela Emenda Constitucional no 45, ocorreu uma mudança de paradigma na gestão do Poder Judiciário brasileiro, com a implantação de ações estratégicas, as quais visaram realizar o planejamento, o controle e implantar novas políticas judiciárias. Outro aspecto importante da reforma foi dotar o Judiciário de mecanismos administrativos que resultem em maior eficiência e celeridade processual, além de assegurar a autonomia e independência dos magistrados e ampliar o acesso da população à justiça.

Com as alterações legislativas, o planejamento e o controle administrativo do Poder Judiciário passaram a ser realizados pelo CNJ, órgão que recebeu do poder constituinte reformador a incumbência de fiscalizar e contribuir com o planejamento dos tribunais no Brasil. A criação de um órgão fiscalizador foi uma condição fundamental apontada pelo governo para que esse núcleo estratégico pudesse se tornar mais transparente e fosse submetido a algum nível de controle da sociedade (Renault, 2005).

No contexto da reforma do Judiciário, o tema transparência teve lugar de destaque. Esse destaque decorreu da própria conjuntura histórica brasileira, a qual guarda fortes resquícios do patrimonialismo, do clientelismo, do nepotismo e da corrupção. Matias-Pereira (2009) e Lustosa da Costa (2010) destacam que a corrupção, principalmente no caso brasileiro, em que a mesma é um problema grave e estrutural da sociedade e do sistema político nacional, apresenta-se como um fenômeno que enfraquece a democracia, a confiança no Estado, a legitimidade dos governos e a moral pública.

No que tange à eficiência e celeridade processual, diversas medidas foram adotadas no bojo da reforma, podendo ser destacada a criação de um plano de metas, por parte do CNJ, com a finalidade de atingir os resultados esperados pela instituição.

Outro aspecto fundamental da reforma foi a afirmação dos princípios constitucionais da autonomia e independência dos magistrados, os quais são imprescindíveis para a consagração da separação dos poderes. Além disso, foram estabelecidos critérios unificados para o ingresso na magistratura, além de reformas que dotaram o Poder Judiciário de maior autonomia financeira, como forma de efetivar o princípio da separação dos poderes.

Por fim, outro ponto fundamental desse processo foi a busca pela universalização do acesso à justiça, por meio do fortalecimento das defensorias públicas e dos juizados especiais. 
Com isso, as antigas práticas administrativas do Poder Judiciário começaram a ser fiscalizadas pelo órgão recém-criado, o qual impôs uma série de metas aos tribunais brasileiros, visando, sobretudo, tornar a justiça brasileira mais célere e transparente. Além disso, novos mecanismos de gestão foram implantados, instituições foram fortalecidas, com o escopo de ampliar o acesso à justiça no País, além de tornar a prestação jurisdicional, serviço público essencial à democracia, mais ágil, eficaz e menos onerosa para a sociedade brasileira.

\section{O Conselho Nacional de Justiça}

O CNJ, criado em 31 de dezembro de 2004, no bojo da reforma do Judiciário, é o órgão desse poder responsável pela reformulação de seus quadros e dos mecanismos de ação e controle, notadamente no que tange à transparência administrativa e processual.

Sediado em Brasília-DF e atuando em todo território nacional, o conselho visa, por meio de ações de planejamento, coordenação e controle administrativo, aperfeiçoar a prestação jurisdicional, tornando-a mais eficiente e eficaz.

Essas diretrizes estão expostas na própria missão do órgão, a qual objetiva contribuir para que a prestação jurisdicional seja realizada com moralidade, eficiência e efetividade, em benefício da sociedade. Já a sua visão é ser um instrumento efetivo de desenvolvimento do Poder Judiciário.

Dentre as diretrizes do CNJ, podemos destacar: a) planejamento estratégico, controle e proposição de políticas judiciárias; b) modernização tecnológica do Judiciário; c) ampliação do acesso à justiça, pacificação e responsabilidade social; d) garantia de efetivo respeito às liberdades públicas e execuções penais.

Com o objetivo de implementar essas diretrizes, o CNJ tem estabelecido metas anuais para os tribunais brasileiros, as quais definem indicadores de eficiência, produtividade e qualidade para o Poder Judiciário, como forma de tornar o serviço público de justiça mais efetivo.

O ousado plano de metas anuais teve início em 2009. O escopo deste trabalho foi analisar as metas estabelecidas para os anos de 2012 e 2013, tendo em vista que as metas estabelecidas para os anos de 2009 a 2011 encontram-se em fase de compilação de resultados.

As metas para os anos de 2012 e 2013 foram definidas pelos presidentes e representantes dos tribunais do País durante o V Encontro Nacional do Judiciário, realizado na cidade de Porto Alegre/RS, nos dias 17 e 18 de novembro de 2011. 
Para o ano de 2012, foram definidas cinco metas gerais, ou seja, de cumprimento obrigatório para todos os tribunais do País. Além delas, outras quatorze metas específicas, direcionadas para cada segmento da Justiça, foram estabelecidas para o citado ano. Já para o ano de 2013, temos dezenove metas, sendo quatro gerais e quinze específicas.

A seguir, será abordada a metodologia empregada para a análise dos dados descritos, para, em seguida, ser iniciado o estudo pormenorizado de cada uma das metas, como forma de justificar a atribuição de determinado indicador. Ao final, chegar-se-á às considerações finais sobre os objetivos centrais das metas estabelecidas pelo CNJ para os anos de 2012 e 2013.

\section{Metodologia}

Para atingir os objetivos propostos, utilizou-se como método de pesquisa a análise de conteúdo, a qual deve basear-se em uma definição precisa dos objetivos da pesquisa, que variam em cada análise e condicionam a diferença das técnicas utilizadas (BARDIN, 2002).

Para Bardin (2002), a fase da organização da análise estrutura-se em três polos cronológicos: pré-análise (identificação e pré-seleção dos documentos por meio da busca e da leitura superficial dos mesmos); exploração do material (análise e seleção final do material pela leitura completa dos documentos); e tratamento dos resultados (a inferência e a interpretação).

Para a escolha dos documentos, foram observadas as regras da exaustividade, representatividade, homogeneidade e da pertinência (BARDIN, 2002), tendo em vista que: a) a análise concentrou-se em todas as metas propostas pelo CNJ para o período de 2012/2013 (regra da exaustividade); b) o conjunto de metas é representativo para analisar o fenômeno estudado (regra de representatividade); c) os documentos obedecem a critérios precisos de escolha, não apresentando singularidades fora dos critérios de análise (regra da homogeneidade); d) as metas do CNJ são documentos adequados, enquanto fonte de informação, para a análise do objetivo do estudo (regra da pertinência).

Com o escopo de analisar as metas a partir do método de pesquisa escolhido, observando-se as regras propostas por Bardin (2002), serão apresentados dois quadros (Quadro 1 e Quadro 2), nos quais as metas propostas pelo CNJ, para o biênio de 2012/2013, foram sistematizadas por meio de categorias que se relacionam com o objetivo proposto e os indicadores de eficácia, eficiência e/ou efetividade predominante: 


\section{Quadro 1: Metas para o ano de 2012}

\begin{tabular}{|c|c|c|}
\hline Metas & Objetivo & Indicador \\
\hline $\begin{array}{l}\text { Meta } 1 \\
\text { (Geral) }\end{array}$ & $\begin{array}{l}\text { Julgar mais processos de conhecimento do que os distribuídos em } \\
2012 .\end{array}$ & Eficácia \\
\hline $\begin{array}{l}\text { Meta } 2 \\
\text { (Geral) }\end{array}$ & $\begin{array}{l}\text { Julgar, até } 31 / 12 / 2012 \text {, pelo menos, } 80 \% \text { dos processos distribuídos } \\
\text { em } 2007 \text {, no Superior Tribunal de Justiça; } 70 \% \text {, em } 2009 \text {, na Justiça Militar da } \\
\text { União; } 50 \% \text {, em 2007, na Justiça Federal; } 50 \% \text {, de } 2007 \text { a 2009, nos Juizados } \\
\text { Especiais Federais e Turmas Recursais Federais; } 80 \% \text {, em 2008, na Justiça do } \\
\text { Trabalho; } 90 \% \text {, de } 2008 \text { a } 2009 \text {, na Justiça Eleitoral; } 90 \% \text {, de } 2008 \text { a } \\
2010 \text {, na Justiça Militar dos Estados; e } 90 \% \text {, em 2007, nas Turmas Recursais } \\
\text { Estaduaise no 2\% Grau da Justiça Estadual. }\end{array}$ & Eficácia \\
\hline $\begin{array}{l}\text { Meta } 3 \\
\text { (Geral) }\end{array}$ & $\begin{array}{l}\text { Tornar acessíveis as informações processuais nos portais da rede mundial } \\
\text { de computadores (internet), com andamento atualizado e conteúdo das } \\
\text { decisões dos processos, respeitando o segredo de justiça. }\end{array}$ & Eficácia/Eficiência \\
\hline $\begin{array}{l}\text { Meta } 4 \\
\text { (Geral) }\end{array}$ & $\begin{array}{l}\text { Constituir Núcleo de Cooperação Judiciária e instituir a figura do juiz de } \\
\text { cooperação. }\end{array}$ & Eficácia/Eficiência \\
\hline $\begin{array}{l}\text { Meta } 5 \\
\text { (Geral) }\end{array}$ & $\begin{array}{l}\text { Implantar sistema eletrônico para consulta à tabela de custas e emissão de } \\
\text { guia de recolhimento. }\end{array}$ & Eficácia/Eficiência \\
\hline $\begin{array}{l}\text { Meta } 6 \\
\text { (JME) }\end{array}$ & $\begin{array}{l}\text { Implantar sistema de videoconferência em pelo menos uma unidade } \\
\text { judiciária, para oitiva de testemunhas, em cooperação com outros } \\
\text { segmentos de justiça. }\end{array}$ & Eficácia/Eficiência \\
\hline $\begin{array}{l}\text { Meta } 7 \\
\text { (JME) }\end{array}$ & $\begin{array}{l}\text { Implantar projeto-piloto do processo judicial eletrônico em pelo menos } \\
\text { uma unidade judiciária. }\end{array}$ & Eficácia/Eficiência \\
\hline $\begin{array}{l}\text { Meta } 8 \\
\text { (JME) }\end{array}$ & $\begin{array}{l}\text { Implantar o processo eletrônico em pelo menos cinco rotinas } \\
\text { administrativas. }\end{array}$ & Eficácia/Eficiência \\
\hline $\begin{array}{l}\text { Meta } 9 \\
\text { (JME) }\end{array}$ & $\begin{array}{l}\text { Implantar sistema de registro audiovisual de audiências em } 100 \% \text { das } \\
\text { unidades judiciárias de } 10 \text { Grau. }\end{array}$ & Eficácia/Eficiência \\
\hline $\begin{array}{l}\text { Meta } 10 \\
\text { (JF) }\end{array}$ & $\begin{array}{l}\text { Designar } 10 \% \text { a mais de audiências de conciliação do que as designadas } \\
\text { no ano anterior (2011). }\end{array}$ & Eficácia \\
\hline $\begin{array}{l}\text { Meta } 11 \\
\text { (JF) }\end{array}$ & $\begin{array}{l}\text { Implantar gestão por processos de trabalho (gerenciamento de rotinas) } \\
\text { em } 50 \% \text { das turmas recursais. }\end{array}$ & Eficácia/Eficiência \\
\hline $\begin{array}{l}\text { Meta } 12 \\
(\mathrm{JE})\end{array}$ & $\begin{array}{l}\text { Realizar pesquisa sobre a qualidade da prestação dos serviços e } \\
\text { satisfação do cidadãonos tribunais eleitorais. }\end{array}$ & Efetividade \\
\hline $\begin{array}{l}\text { Meta } 13 \\
(\mathrm{JE})\end{array}$ & $\begin{array}{l}\text { Implantar pelo menos uma iniciativa de promoção da cidadania voltada } \\
\text { para jovens. }\end{array}$ & Efetividade \\
\hline $\begin{array}{l}\text { Meta } 14 \\
\text { (JT) }\end{array}$ & $\begin{array}{l}\text { Estabelecer o Programa de Controle Médico de Saúde Ocupacional } \\
\text { (PCMSO) e Programa de Prevenção de Riscos Ambientais (PPRA) em } \\
\text { pelo menos } 60 \% \text { das unidades judiciárias e administrativas. }\end{array}$ & Eficácia \\
\hline $\begin{array}{l}\text { Meta } 15 \\
\text { (JT) }\end{array}$ & $\begin{array}{l}\text { Capacitar, com carga-horária mínima de } 20 \text { horas, } 20 \% \text { dos magistrados } \\
\text { e } 20 \% \text { dos servidores na utilização do Processo Judicial Eletrônico (PJE) } \\
\text { eem gestão estratégica. }\end{array}$ & Eficácia/Eficiência \\
\hline $\begin{array}{l}\text { Meta } 16 \\
\text { (JT) }\end{array}$ & $\begin{array}{l}\text { Implantar o Processo Judicial Eletrônico (PJE) em, pelo menos, } 10 \% \text { das } \\
\text { Varas de Trabalho de cada tribunal. }\end{array}$ & Eficácia/Eficiência \\
\hline $\begin{array}{l}\text { Meta } 17 \\
\text { (JT) }\end{array}$ & $\begin{array}{l}\text { Aumentar em 10\% o quantitativo de execuções encerradas em relação } \\
\text { a } 2011 .\end{array}$ & Eficácia \\
\hline $\begin{array}{l}\text { Meta } 18 \\
\text { (JT) }\end{array}$ & $\begin{array}{l}\text { Executar, até setembro de } 2012 \text {, pelo menos } 60 \% \text { do orçamento anual } \\
\text { disponível, excluídas as despesas de pessoal. }\end{array}$ & Eficácia/Eficiência \\
\hline $\begin{array}{l}\text { Meta } 19 \\
\text { (JMU) }\end{array}$ & $\begin{array}{l}\text { Desenvolver normas e políticas de gestão documental para a Justiça } \\
\text { Militar daUnião. }\end{array}$ & Eficácia/Eficiência \\
\hline
\end{tabular}

Fonte: Elaboração própria com informações obtidas em www.cnj.jus.br

Siglas: JME (Justiça Militar Estadual), JF (Justiça Federal), JE (Justiça Eleitoral), JT (Justiça do Trabalho), JMU (Justiça Militar da União), STJ (Superior Tribunal de Justiça). 
Quadro 2: Metas para o ano de 2013

\begin{tabular}{|c|c|c|}
\hline Meta & Objetivo central & Indicador \\
\hline $\begin{array}{l}\text { Meta } 1 \\
\text { (Geral) }\end{array}$ & $\begin{array}{l}\text { Julgar mais processos de conhecimento do que os distribuídos em } \\
2013 .\end{array}$ & Eficácia \\
\hline $\begin{array}{l}\text { Meta } 2 \\
\text { (Geral) }\end{array}$ & $\begin{array}{l}\text { Julgar, até } 31 / 12 / 2013 \text {, pelo menos, , } 80 \% \text { dos processos distribuídos em } \\
2008 \text {, no Superior Tribunal de Justiça; } 70 \% \text {, em 2010, na Justiça Militar } \\
\text { da União; } 50 \% \text {, e 2008, na Justiça Federal; } 50 \% \text {, em 2010, nos Juizados } \\
\text { Especiais Federais e Turmas Recursais Federais; } 80 \% \text {, em 2009, na Justiça } \\
\text { do Trabalho; } 90 \% \text {, em 2010, na Justiça Eleitoral; } 90 \% \text {, em 2011, na Justiça } \\
\text { Militar dos Estados; e 90\%, em 2008, nas Turmas Recursais Estaduais e } \\
\text { no 20 Grau da Justiça Estadual. }\end{array}$ & Eficácia \\
\hline $\begin{array}{l}\text { Meta } 3 \\
\text { (JME) }\end{array}$ & Julgar $90 \%$ dos recursos cíveis e criminais em até 120 dias. & Eficácia \\
\hline $\begin{array}{l}\text { Meta } 4 \\
\text { (JME) }\end{array}$ & $\begin{array}{l}\text { Implantar o processo judicial eletrônico em } 25 \% \text { das unidades } \\
\text { judiciárias. }\end{array}$ & Eficácia/Eficiência \\
\hline Meta 5 (JF) & $\begin{array}{l}\text { Designar } 10 \% \text { a mais de audiências de conciliação do que as designadas } \\
\text { no ano anterior (2012). }\end{array}$ & Eficácia \\
\hline Meta 6 (JF) & $\begin{array}{l}\text { Implementar gestão por processos de trabalho (gerenciamento de } \\
\text { rotinas) em } 100 \% \text { das turmas recursais. }\end{array}$ & Eficácia/Eficiência \\
\hline Meta 7 (JE) & $\begin{array}{l}\text { Modelar pelo menos } 5 \text { processos de trabalho das unidades judiciárias } \\
\text { de } 19 \text { Grau da Justiça Eleitoral. }\end{array}$ & Eficácia/Eficiência \\
\hline Meta 8 (JE) & $\begin{array}{l}\text { Implantar e divulgar a "Carta de Serviços" do 2 Grau da Justiça } \\
\text { Eleitoral. }\end{array}$ & Efetividade \\
\hline Meta 9 (JT) & $\begin{array}{l}\text { Implementar o Programa de Controle Médico de Saúde Ocupacional } \\
\text { (PCMSO) e Programa de Prevenção de Riscos Ambientais (PPRA) em } \\
100 \% \text { das unidades judiciárias e administrativas. }\end{array}$ & Eficácia \\
\hline Meta $10(\mathrm{JT})$ & $\begin{array}{l}\text { Realizar adequação ergonômica em } 100 \% \text { das unidades judiciárias de } \\
1 \% \text { e } 2 \% \text { Grau. }\end{array}$ & Eficácia \\
\hline Meta $11(\mathrm{JT})$ & $\begin{array}{l}\text { Capacitar, com duração mínima de } 20 \text { horas, } 50 \% \text { dos magistrados e } \\
50 \% \text { dos servidores na utilização do Processo Judicial Eletrônico (PJE) e } \\
\text { em gestão estratégica. }\end{array}$ & Eficácia/Eficiência \\
\hline Meta $12(\mathrm{JT})$ & $\begin{array}{l}\text { Implantar o Processo Judicial Eletrônico (PJE) em, pelo menos, } 40 \% \text { das } \\
\text { Varas de Trabalho de cada tribunal. }\end{array}$ & Eficácia/Eficiência \\
\hline Meta $13(\mathrm{JT})$ & $\begin{array}{l}\text { Aumentar em 15\% o quantitativo de execuções encerradas em relação } \\
\text { a } 2011 .\end{array}$ & Eficácia \\
\hline Meta $14(\mathrm{JT})$ & $\begin{array}{l}\text { Executar, até setembro de } 2013 \text {, pelo menos } 65 \% \text { do orçamento anual } \\
\text { disponivel, excluídas as despesas com pessoal. }\end{array}$ & Eficácia/Eficiência \\
\hline $\begin{array}{l}\text { Meta } 15 \\
(\mathrm{JMU})\end{array}$ & $\begin{array}{l}\text { Desenvolver versão-teste de sistema de gestão eletrônica administrativa } \\
\text { e judicial. }\end{array}$ & Eficácia/Eficiência \\
\hline $\begin{array}{l}\text { Meta } 16 \\
\text { (Geral) }\end{array}$ & Fortalecer a unidade de controle interno no Tribunal. & Eficácia \\
\hline $\begin{array}{l}\text { Meta } 17 \\
\text { (Geral) }\end{array}$ & Desenvolver, nacionalmente, sistemas efetivos de licitação e contratos. & Eficiência \\
\hline $\begin{array}{l}\text { Meta } 18(\mathrm{JF}, \\
\text { JEST e STJ) }\end{array}$ & $\begin{array}{l}\text { Identificar e julgar, até } 31 / 12 / 2013 \text {, as ações de improbidade adminis- } \\
\text { trativa e ações penais relacionadas a crimes contra a administração } \\
\text { pública, distribuídas até } 31 / 12 / 2011 \text {. }\end{array}$ & Eficácia \\
\hline $\begin{array}{l}\text { Meta } 19 \text { (JF, } \\
\text { JEST e JE) }\end{array}$ & $\begin{array}{l}\text { Realizar parcerias entre o Conselho Nacional de Justiça, os Tribunais de } \\
\text { Justiça, os Tribunais Federais, os Tribunais Regionais Eleitorais e os } \\
\text { Tribunais de Contas, para o aperfeiçoamento e alimentação do Cadastro } \\
\text { Nacional de Condenações Cíveis por ato de improbidade administrativa. }\end{array}$ & Eficácia \\
\hline
\end{tabular}

Fonte: Elaboração própria com as informações obtidas em www.cnj.jus.br

Siglas: JME (Justiça Militar Estadual), JF (Justiça Federal), JE (Justiça Eleitoral), JT (Justiça do Trabalho), JMU (Justiça Militar da União), JEST (Justiça Estadual) e STJ (Superior Tribunal de Justiça). 
A codificação do material seguiu a lógica da agregação em unidades, visando uma descrição exata das características do conteúdo (BARDIN, 2002). Para tanto, o recorte, ou seja, a escolha das unidades restringiu-se às metas do CNJ para o biênio 2012/2013. Já a enumeração foi realizada pela regra de contagem do tipo frequência, buscando encontrar os indicadores mais utilizados. Por fim, o material foi classificado e agregado por meio de categorias, as quais buscaram descrever as várias faces do processo de reforma do Poder Judiciário no Brasil.

\section{Análise dos dados}

Por meio da aplicação dos procedimentos de análise de conteúdo propostos na metodologia, chegou-se à definição de cinco categorias de dados, as quais traduzem as 34 metas propostas pelo CNJ para os anos de 2012 e 2013. O Quadro 3 esquematiza as categorias identificadas e as relaciona com os indicadores de eficácia, eficiência e efetividade, buscando sistematizar os objetivos da reforma do Poder Judiciário brasileiro:

Quadro 3: Categorias de dados, metas do CNJ e indicadores de eficácia, eficiência e efetividade

\begin{tabular}{|l|l|l|}
\hline Categorias & Ano/Metas & Finalidade \\
\hline Celeridade Processual & $\begin{array}{l}2012 \text { (metas um, dois, dez e dezes- } \\
\text { sete); } 2013 \text { (metas um, dois, três, } \\
\text { cinco, treze e dezoito). }\end{array}$ & Eficácia \\
\hline Gestão do Poder Judiciário & $\begin{array}{l}2012 \text { (metas quatro, onze, dezoito } \\
\text { e dezenove); 2013 (metas seis, sete, } \\
\text { quatorze, quinze, dezesseis e dezessete). }\end{array}$ & \\
\hline Capacitação/Saúde dos Servidores & $\begin{array}{l}2012 \text { (metas quatorze e quinze); 2013 } \\
\text { (metas nove, deze onze). }\end{array}$ & Eficácia/Eficiência \\
\hline Informatização/Transparência & $\begin{array}{l}2012 \text { (metas três, cinco, seis, sete, } \\
\text { oito, nove e dezesseis); 2013 (metas } \\
\text { quatro, doze e dezenove) }\end{array}$ & Eficácia/Eficiência \\
\hline Responsabilidade Social & $\begin{array}{l}2012 \text { (me tas doze e treze); 2013 } \\
\text { (meta oito). }\end{array}$ & Efetividade \\
\hline
\end{tabular}

Fonte: Elaboração própria.

A primeira categoria de metas identificadas foi a celeridade processual. Entre as metas estudadas, dez delas tiveram como finalidade dar efetividade ao princípio da celeridade processual, o qual, segundo o art. 50, LXXVIII, da Constituição Federal, garante a todos, no âmbito judicial e administrativo, a razoável duração dos processos e os meios que garantam a celeridade de sua tramitação.

Assim, visando desafogar os tribunais do País e satisfazer a pretensão da sociedade brasileira que clamava por um Judiciário mais célere, todos os tribunais brasileiros 
passaram a ter metas que privilegiam a eficácia no tocante ao julgamento dos processos, como forma de atender às demandas da sociedade.

O cumprimento dessas metas é considerado de suma importância, pois a lentidão na tramitação dos processos é apontada por grande parte da população como o grande mal do processo judicial brasileiro (RenAult, 2005).

Uma segunda categoria de metas identificadas engloba dez orientações, as quais tiveram como finalidade precípua desenvolver novos métodos de gestão administrativa e judicial no Poder Judiciário, que vão desde a constituição de núcleos de cooperação judiciária até o desenvolvimento de versão-teste de sistema de gestão eletrônica administrativa e judicial, como forma de modernizar os processos internos do Judiciário nacional.

Todas as metas repercutem tanto na eficácia organizacional, pois visam contribuir para que os tribunais do País atinjam sua missão institucional, quanto na eficiência, tendo em vista que essas medidas poderão resultar em ganho econômico para os órgãos desse poder, a médio e longo prazo.

Outra categoria identificada resulta da preocupação do CNJ com a capacitação e a saúde dos servidores e magistrados, sendo representadas pelas metas 14 e 15 de 2012 e pelas metas 9, 10 e 11 de 2013. O objetivo dessas metas é proporcionar treinamento para esses profissionais, preparando-os para a gestão dos tribunais e demais órgãos vinculados à estrutura desse poder, além de primar pela saúde preventiva dos mesmos, diminuindo o absenteísmo nesses órgãos.

Essas metas também trabalham com os dois indicadores, eficiência e eficácia, conjuntamente. O primeiro indicador é verificado, tendo em vista que a gestão dos órgãos judiciais, em tese, será mais eficiente, quando a administração dos mesmos ficar a cargo de servidores devidamente treinados para exercerem essa função gerencial. Por outro lado, o conjunto de medidas adotado por um gestor capacitado trará resultados, a médio e longo prazo, condizentes com os objetivos estratégicos da organização. Além disso, a criação do PCMSO e PPRA, além da adequação ergonômica das unidades judiciárias, também traz reflexos sensíveis nesses dois indicadores.

Portanto, as cinco metas da categoria capacitação/saúde buscaram melhorar os indicadores de eficiência e eficácia, na gestão do Poder Judiciário brasileiro, por meio da capacitação dos magistrados, com treinamento em administração judiciária, e de servidores, com cursos ligados à gestão de pessoas e processos de trabalho. Soma-se a isso, o investimento na saúde do servidor, fato que também repercute na eficiência e eficácia dos órgãos judiciários.

A quarta categoria identificada trabalha com duas vertentes - informatização e transparência - as quais caminham lado a lado, facilitando o acesso dos operadores 
do Direito às informações judiciais, além de propiciar à sociedade acesso a uma variedade de dados que antes eram restritos aos servidores e magistrados.

Verificou-se que, entre as metas propostas, dez têm como objetivo informatizar diversos procedimentos inerentes à atividade jurisdicional, além de dar transparência à prestação jurisdicional por meio do acesso às informações processuais na internet.

Essa categoria também trabalha com os indicadores de eficácia e eficiência. No primeiro viés, ao informatizar diversos procedimentos jurisdicionais e dar maior transparência às rotinas administrativas desse núcleo estratégico do Estado, estar-se-á combatendo uma das principais mazelas do Poder Judiciário, que é a obsolescência administrativa. Já no segundo, a informatização de grande parte dos procedimentos trará, a médio e longo prazo, economia na utilização de recursos, tornando o Judiciário mais produtivo.

Por fim, a última categoria trabalha com um tema bastante recorrente, que é a responsabilidade social, a qual busca dar efetividade à prestação jurisdicional, com o atendimento das necessidades da sociedade brasileira pelos serviços prestados pelo Judiciário nacional, seja por meio da divulgação dos serviços prestados pela Justiça Eleitoral de $2^{\circ}$ grau, ou pela implantação de medidas que promovam a cidadania entre os jovens.

\section{Considerações finais}

O presente trabalho originou-se da indagação do pesquisador sobre as peculiaridades que cercam a reforma do Poder Judiciário, notadamente as principais características das metas estabelecidas pelo CNJ para os anos de 2012 e 2013. O foco não foi verificar o cumprimento das citadas metas, mas, sim, analisá-las, qualitativamente, buscando compreender os objetivos centrais desse processo.

Iniciou-se analisando o panorama da reforma gerencial do Estado brasileiro, a qual tem seu nascedouro em 1995, e como esse processo repercutiu num dos núcleos estratégicos do Estado, o Poder Judiciário.

Analisou-se também um dos dilemas da citada reforma: o embate entre o modelo gerencial, com foco na eficácia organizacional, versus o modelo fiscal, com viés economicista, buscando a eficiência administrativa, os quais serviram de norte na busca dos resultados do estudo.

Ao analisar o conjunto de metas propostas pelo CNJ para os anos em questão, verificou-se que três categorias (gestão do Poder Judiciário; capacitação/saúde dos servidores; informatização/transparência), compreendendo vinte e cinco metas, trabalham com indicadores de eficácia e eficiência, demonstrando um 
viés gerencial da reforma. Tais metas buscam atingir, conjuntamente, os objetivos desse núcleo estratégico, oferecendo à sociedade um serviço público mais transparente, moderno e menos oneroso.

Diferente do que foi observado por Sena, Silva e Luquini (2012), não houve a inserção de metas com viés eminentemente fiscal no biênio estudado, fato que corrobora a conclusão de que esse não é o objetivo central do processo de reforma do Poder Judiciário no Brasil.

Já a segunda categoria, a qual engloba a celeridade processual, corresponde a um conjunto de metas que respondem à principal demanda da sociedade brasileira: a razoável duração dos processos. Percebe-se, novamente, que o principal objetivo dessas dez metas é atingir um dos objetivos desse núcleo estratégico do Estado, demonstrando, novamente, o viés gerencial das metas em questão.

Por fim, verifica-se a inclusão de três metas que visam dotar o Poder Judiciário de efetividade junto à sociedade brasileira, ou melhor, visam criar valor social para esse núcleo estratégico do Estado. É importante consignar que todas as metas categorizadas como de responsabilidade social são voltadas para a Justiça Eleitoral.

Pelo método proposto, conclui-se que a reforma do Poder Judiciário no Brasil é uma reforma com viés gerencial, pois a redução dos custos desse serviço público não é objetivo central da mesma. Assim, os principais esforços do CNJ se concentraram em obter melhores outputs, ou seja, alcançar os objetivos estratégicos dessa esfera de poder estatal.

Apesar da conclusão verificada, o processo de reforma não está encerrado. Novas metas serão estipuladas para os próximos anos, fato que poderá alterar o norte do processo. Além disso, com a divulgação dos primeiros resultados relativos ao cumprimento das metas estabelecidas para os anos de 2009 a 2011, novos leques de pesquisa serão abertos.

Ressalta-se, por fim, o fato de a sociedade brasileira ser inserida nesse processo pela inclusão das metas de responsabilidade social, as quais tentam traduzir a efetividade. Fica a ressalva de que tais metas são exclusivas da Justiça Eleitoral, devendo o CNJ expandir esses objetivos para todos os tribunais brasileiros, sob pena de o processo de reforma do Poder Judiciário não atingir a plena efetividade.

Como agenda de pesquisa, sugere-se a realização de uma descrição da reforma do Judiciário no Brasil sob outras correntes teóricas e metodológicas, além da análise do índice de cumprimento das metas estabelecidas pelo CNJ. 


\section{Referências bibliográficas}

Abrucio, Fernando Luiz. Os avanços e os dilemas do modelo pós-burocrático: a reforma da administração pública à luz da experiência internacional recente: In: Bresser Pereira, L. C; Spink, P. (ORG). Reforma do Estado e Administração Pública Gerencial. 7. ed. Rio de Janeiro: Editora FGV, 2006.

Bardin, Laurence. Análise de conteúdo. Lisboa: Edições 70, 2002.

Bresser Pereira, Luiz Carlos. Da Administração Pública Burocrática à gerencial: In: Bresser Pereira, L. C; Spink, P. (ORG). Reforma do Estado e Administração Pública Gerencial. 7. ed. Rio de Janeiro: Editora FGV, 2006.

. Gestão do Setor Público: estratégia e estrutura para um novo Estado: In: Bresser Pereira, L. C; Spink, P. (ORG). Reforma do Estado e Administração Pública Gerencial. 7. ed. Rio de Janeiro: Editora FGV, 2006.

DI PIETRo, Maria Sylvia Zanella. Direito Administrativo. 14.ed. São Paulo: Atlas, 2002. KeInert, Tânia Margarete Mezzomo. A Administração Pública no Brasil: Crises e Mudanças de Paradigmas. 2 ed. São Paulo: Annablume-Fapesp, 2006.

LACOMBE, Francisco J. M. e HEILBORN, Gilberto L. J. Administração princípios $e$ tendências. 1. ed. - São Paulo : Saraiva, 2003.

LUSTOSA DA COSTA, Frederico. Reforma do Estado e Contexto Brasileiro: crítica do paradigma gerencialista. Rio de Janeiro: Editora FGV, 2010.

Machiavelu, N. di B. dei. O príncipe. Porto Alegre: L\&PM, 2006.

Matias-pereira, José. Curso de Administração Pública: foco nas instituições e ações governamentais. 2 ed. São Paulo: Atlas, 2009.

Maximıano, Antonio Cesar Amaru. Teoria Geral da Administração. São Paulo: Atlas, 2006.

Moraes, Alexandre de. Reforma Administrativa: Emenda Constitucional 19/98. 4 ed. São Paulo: Atlas, 2001.

OsBorne, David; GAEBLER, Ted. Reinventing Government: how the entrepreneurial spirit is transforming the public sector. Reading, MA: Addison-Wesley, 1992.

Paula, Ana Paula Paes de. Por uma Nova Gestão Pública: limites e potencialidades da experiência contemporânea. Rio de Janeiro: Editora FGV, 2005.

Pinheiro, Armando Castelar. Judiciário, Reforma e Economia: a visão dos magistrados. In: Texto para Discussão no 966. Rio de Janeiro, IPEA, 2003.

Renault, Sérgio Rabello Tamm. A Reforma do Poder Judiciário sob a ótica do Governo Federal. In: Revista do Serviço Público v. 56, no 2. Brasília: ENAP, 2005.

SECCHI, Leonardo. Modelos Organizacionais e Reformas da Administração Pública. Revista de Administração Pública, v. 43, no 2. Rio de Janeiro, 2009.

SenA, Gabriel Astoni; sILvA, Edson Arlindo; LUQUINI, Roberto de Almeida. A Reforma do Poder Judiciário no Brasil: uma análise a partir do modelo gerencial. In: Revista de Ciências da Administração. v. 14, no 33. Florianópolis: UFSC, 2012. 
TORREs, Marcelo Douglas de Figueiredo. Estado, democracia e administração pública no Brasil. Rio de Janeiro: FGV, 2004.

\section{Gabriel Astoni Sena}

Mestre em Administração pela Universidade Federal de Viçosa, Minas Gerais (UFV) e Analista Judiciário do Tribunal Regional Eleitoral de Minas Gerais (TRE-MG). Contato: astonisena@gmail.com 